\title{
INTERTEXTUALIDADES DEL 98: UNAMUNO Y MACHADO
}

\author{
Luis Fernández Gallardo \\ UNED. Albacete
}

lfernandez@albacete.uned.es

\section{UnAMUno y MACHADO ANTE EL 98}

La índole contradictoria, paradójica, de la personalidad de Unamuno se extiende asimismo a su adscripción a la generación o grupo del 98. Ciertamente, su fuerte individualidad, su afán por singularizarse, por conquistar la fama y la gloria literarias, dificultaban su encaje en cualquier empresa colectiva. Una poderosísima personalidad, un talante ${ }^{1}$ que se mantiene firme e imbatible en su empeño combativo, agónico, era incompatible con las concesiones y limitaciones que impone el grupo. Azorín, en el artículo en que consagrara la idea de generación del 98, tras los tanteos e intuiciones de Oliver, ${ }^{2}$ Gabriel Maura y González Blanco, ofrece la primera nómina canónica del grupo: Unamuno, en segundo lugar, tras Valle-Inclán. ${ }^{3}$

\footnotetext{
1 Término que últimamente, por razones que no vienen al caso, se ha trivializado, pero que ha servido para caracterizar precisamente el sentimiento religioso de Unamuno. Véanse las consideraciones «Para una teoría del talante» y su aplicación a Unamuno en Aranguren, José Luis L. (1980): Catolicismo y protestantismo como formas de existencia (1952), Madrid, Alianza Editorial, pp. 15-29 y 239-259.

2 Reivindica la aportación de Miquel dels Sants Oliver (1864-1920) en la gestación del concepto de generación del 98 Rodríguez PuÉRTolas, Julio (1999): El desastre en sus textos. La crisis del 98 vista por los escritores coetáneos, Madrid, Akal, pp. 232-233.

3 «Hombres de la generación de 1898 son Valle-Inclán, Unamuno, Benavente, Baroja, Bueno, Maeztu, Rubén Darío». [AzoRín (1971): «La generación de 1898» (1913), Clásicos y modernos, Buenos Aires, Losada, p. 174]. En las nóminas propuestas en dos estudios hechos con sólidos instrumentos conceptuales y aparecidos casi al mismo tiempo, se advierten estimaciones diferentes con relación a la posición de Unamuno. Por un lado, pasa a ocupar el primer puesto en la nómina generacional [SALINAS, Pedro (1985): «El concepto de generación literaria aplicado a la del 98» (1935), Literatura española siglo XX, Madrid, Alianza Editorial, p. 26]; por otro,
} 
El germen de la generación, el grupo de los tres (Azorín, Baroja, Maeztu) ${ }^{4}$ le envió una carta reconociendo su magisterio e invitándolo a participar en las empresas proyectadas para la regeneración de España. El entonces rector de Salamanca aun alentando el propósito que guiaba a estos jóvenes (pues ciertamente encajaba con sus exhortaciones a la juventud española), se mantuvo al margen de tales proyectos. Se comprometía a apoyarlos, se solidarizaba con ellos, pero alegaba que las soluciones a los problemas patrios habían de ser de índole espiritual. ${ }^{5}$ Y es que no hay que perder de vista que por aquellos años, Unamuno se sentía llamado a una suerte de misión mesiánica en España, vocación que se alzaba sobre la íntima convicción de su valía. ${ }^{6}$ Quien aspiraba a cumplir tan alta misión difícilmente podía condescender a los compromisos y limitaciones que imponía la labor de grupo. Así pues, en la primera ocasión que se presentaba de anudar los vínculos propios de una generación literaria, Unamuno reaccionaba con gesto evasivo: sobre las solicitaciones de quienes buscaban afirmarse como colectivo en la vida cultural se imponía una individualidad que no estaba dispuesta a que se diluyera en el grupo el reconocimiento a que aspiraba.

A su vez, la estimación literaria de Unamuno entre los noventayochistas viene a abundar en esa cierta marginalidad respecto del grupo generacional. Sumamente elocuente al respecto es la suerte de Paz en la guerra, ${ }^{7}$ su primera novela (1896), en la cual depositó todas sus esperanzas para su consagración como escritor. ${ }^{8}$ La reacción del grupo de los tres resulta de especial interés. Azorín y Maeztu publicaron duras críticas de la novela. Sin dejar de reconocer que tales juicios surgen de sinceras convicciones estéticas,

se le excluye por razón cronológica, reconociéndosele, eso sí, un papel precursor [JESCHKE, Hans (1954): La generación de 1898 (ensayo de una determinación de su esencia) (1934), Madrid, Editora Nacional, p. 73]. Consagra el liderazgo de Unamuno Laín Entralgo, Pedro (1975): La generación del noventa y ocho, Madrid, Espasa-Calpe, pp. 20-21.

${ }^{4}$ Sobre las vicisitudes del núcleo noventayochista véase GonzÁlez CuEvas, Pedro Carlos (2003): Ramiro de Maeztu. Biografía de un nacionalista español, Madrid, Marcial Pons, pp. 104-106.

5 Véase la carta remitida a Azorín (14 de marzo de 1904), reproducida por RiBbans, Geoffrey (1971): «Unamuno y 'los jóvenes' en 1904», Niebla y soledad. Aspectos de Unamuno y Machado, Madrid, Gredos, p. 69. Inteligente comentario de la cortés negativa de Unamuno en Trapiello, Andrés (1997): Los nietos del Cid. La nueva Edad de oro de la literatura española (1898-1914), Barcelona, Planeta, pp. 205-208. Llama la atención que los argumentos que esgrime Unamuno para mantenerse al margen de las actividades de «Los tres» sean los mismos que en su novela San Manuel Bueno, mártir aduce don Manuel ante las propuestas de Lázaro de fundar un sindicato agrario [Unamuno, Miguel de (1979): San Manuel Bueno, mártir (1933), Madrid, Alianza Editorial, pp. 57-59].

${ }^{6}$ Es sumamente reveladora al respecto la carta que envió a su amigo Pedro Múgica (diciembre de 1903), en que le confiesa sus convicciones y ambiciones. Nada menos que se sentía «un instrumento en manos de Dios y un instrumento para contribuir a la renovación espiritual de España» (cfr. RibBANs, «Unamuno y `los jóvenes'», pp. 69-71, cita en p. 70).

7 Para la recepción inmediata de esta obra véase Rabaté, Colette y Jean-Claude (2009): Miguel de Unamuno. Biografía, Madrid, Taurus, pp. 187-189.

${ }_{8}$ Tras lo que sintió como fiasco, no obtener el premio convocado en 1892 por la Real Academia de la Lengua sobre el Poema de Mío Cid, que recibió, en cambio, Menéndez Pidal, decidiría dejar en un segundo plano la producción puramente académica y erudita para centrarse en su obra de creación. Unamuno había presentado al certamen un meritorio estudio, largo tiempo inédito: UnAmuno, Miguel de (1977): Gramática y glosario del Poema del Cid, ed. Barbara D. Huntley, Pilar Liria, Madrid, Espasa-Calpe. El epistolario incluido en el estudio preliminar (pp. 35-54) permite seguir de cerca las ansiedades y zozobras personales del entonces joven catedrático, que viera en tal premio la ocasión para labrarse un nombre en el mundo literario. 
hay que admitir asimismo un componente de competencia personal. ${ }^{9}$ A la altura del último decenio del siglo XIX, los jóvenes del 98 se esforzaban denonadamente por hacerse un lugar en la sociedad literaria. La descalificación de la obra de un aspirante a formar parte de dicha sociedad no obedecería sino a elemental estrategia competitiva. Baroja, en cambio, si se concede crédito a la evocación de su experiencia en el mundo literario finisecular, no habría tenido noticia de la publicación de Paz en la guerra, dado que entonces, ocupado como estaba en los sucesivos oficios de médico rural y de industrial, no podía estar al tanto de la actualidad literaria. ${ }^{10} \mathrm{~A}$ su vez, las páginas que le dedica a Unamuno dentro del capítulo que versa sobre escritores, bohemios y políticos tiene todas las trazas de un ajuste de cuentas retrospectivo: ni el menor asomo de simpatía por el personaje ${ }^{11}$ en cambio, la ironía y la exactitud de la observación psicológica se aúnan para perfilar un retrato implacable.

De este modo, las relaciones personales de Unamuno con el grupo generacional del 98 en el momento en que habían de anudarse los vínculos de dicha generación se revelaban distantes y no carentes de los roces comprensibles en un medio cultural en que los escritores nóveles habían de competir duramente por labrarse un prestigio. ${ }^{12}$ En un principio, la posición de Unamuno resultaba más bien marginal con respecto al grupo de jóvenes cuyas afinidades establecieron los vínculos que avalarían su pertenencia a una generación literaria. ${ }^{13} \mathrm{Y}$ es que su egotismo exacerbado dificultaba el encaje en la convivencia de grupo. Una anécdota significativa al respecto: cuenta Ricardo Baroja que su hermano Pío hizo las presentaciones oportunas entre Unamuno y Valle-Inclán; durante los minutos que duró el encuentro no pararon ambos de discutir y finalmente se despidieron agriamente. ${ }^{14}$ Ciertamente ese individualismo áspero y arisco no era privativo del escritor vasco: quien se ofreciera a iniciar la amistad entre él y Valle exhibía análogo rechazo a la empresa colectiva. ${ }^{15}$ Por otra parte, razones de índole externa dificultaban la integración de Unamuno en el grupo. El marco de sociabilidad de los jóvenes escritores de entonces era fundamentalmente la tertulia, el ambiente bohemia: ${ }^{16}$ Unamuno veía

9 Azorín calificó el libro de «vulgar, enojoso, sin frescuras de estilo». Tanto él como Maeztu le achacaban asimismo nebulosidades y embrollos (cfr. RABATÉ, 2009: p. 188).

${ }^{10}$ Según la confidencia que hizo a Maeztu, quien se asombraba de que no conociera a Unamuno (BAROJA, Pío (1983): Desde la última vuelta del camino. Memorias, t. IV: Galería de tipos de la época, Madrid, Caro Raggio, p. 155). Y sin embargo, ya en 1900, a raíz de la publicación de Vidas sombrías, mantenían relación epistolar, como indica el propio Baroja (Galería de tipos, p. 169).

${ }^{11}$ Su sobrino Julio reconocería efectivamente tal distancia: «En mi casa ni mi madre ni mis tíos tenían demasiada simpatía por él [= Unamuno].» (CARo Baroja, Julio (1978): Los Baroja, Madrid, Taurus, p. 229).

${ }^{12}$ El contexto de competitividad y dificultades, no sólo literarias, a que se veían enfrentados los jóvenes en la España finisecular sería evocado con exactitud y perspicacia por Baroja (BARoJA, Pío (1982): Desde la última vuelta del camino. Memorias, t. III: Final del siglo XIX y principios del XX, Madrid, Caro Raggio, pp. 7-10).

${ }_{13}$ De nuevo ofrece especial interés la valoración que hizo Baroja de la concurrencia de jóvenes escritores en el Madrid de fines del siglo XIX: «Era la casualidad la que nos reunió por un momento muy corto que terminó en desbandada general.» [BARoJA, Pío (1985): Juventud, egolatría (1917), Madrid, Caro Raggio, p. 126].

14 Baroja, Ricardo (1989): Gente del 98 (1935), ed. P. Caro Baroja, Madrid, Cátedra, p. 88.

15 «Todo lo colectivo me es antipático.» [BARoJA, Pío (1982): Desde la última vuelta del camino. Memorias, t. I: El escritor según él y según los críticos, Madrid, Caro Raggio, p. 166].

${ }^{16}$ Señala la convivencia de las tertulias como primera muestra de las relaciones personales en tanto que requisito generacional SALINAS, «El concepto», p. 30. A su vez, destaca los ambientes bohemios como marco de las relaciones de los jóvenes del 98 Ricardo BARoJA, Gente del 98, pp. 55-62. Baroja caracterizaría a Unamuno como «hombre clásico de tertulia» (Galería de tipos, p. 157). 
limitados sus contactos con tales círculos, dado que residía en Salamanca desde que obtuvo la cátedra de Lengua griega (1891). A su vez, su temperamento se hallaba en las antípodas de la bohemia madrileña finisecular.

Y sin embargo, el propio Unamuno acabaría reconociéndose miembro de la tal generación. Una vez puesta en circulación la idea de una generación del 98, consagrada merced al prestigio que a la altura de 1913 gozaba Azorín, era difícil sustraerse al halago de verse reconocido en un grupo literario que asumía y se arrogaba la conciencia colectiva en un momento decisivo de la historia de España, que se erigía de este modo en una suerte de representante espiritual de la nación. ${ }^{17}$ En efecto, pocos años después de la aparición de los célebres artículos de Azorín, Unamuno aceptaba como un axioma la existencia de una generación del 98 de la que formaba parte, a la vez que los rasgos que se le asignaban. A la imputación de egolatría, respondía con una encendida vindicación de lo que aparecía como rasgo temperamental más acusado de los hombres del 98 y del papel histórico que desempeñó. Y en tal empeño reivindicador se reconoce como miembro de esa juventud que se lanzó impetuosamente en ademán anárquico y anarquista «contra la España constituida». ${ }^{18}$ Sólo tres años después de que Azorín consagrara la idea de generación del 98 , ésta era aceptada por quien se mostrara reacio a cualquier empresa de grupo.

La adscripción de Antonio Machado al grupo en cuestión no deja de ser asimismo irregular. Ausente en la nómina de Azorín, sería incluido, sin embargo, en las propuestas por Jeschke y Salinas. ${ }^{19}$ Ciertamente, el libro Campos de Castilla, publicado en 1912, al punto fue entusiastamente comentado por Azorín en su artículo «El paisaje en los versos», aparecido en el diario $A B C$, el dos de agosto de ese mismo año. ${ }^{20} \mathrm{Si}$ Campos de Castilla reúne la esencia de la sensibilidad paisajística noventayochista, inscrita en el marco de una profunda reflexión sobre el tema de España, habrá que pensar que la ausencia de Machado en la nómina de Azorín se debe a que en la caracterización de éste predominaba la idea de protesta, ${ }^{21}$ no tan perceptible en las estampas paisajísticas que tanto lo cautivaron. Tal vez era demasiado inmediata la aparición de la obra que consagraría la imagen canónica del paisaje castellano para que se valorara su aportación a la crítica de la realidad española. Antonio Machado, de modo análogo a Unamuno, permaneció en

${ }^{17}$ Aunque Baroja se sustrajera a tales encantos, al negar categóricamente la existencia de tal generación (El escritor, p. 157).

${ }^{18}$ Unamuno, Miguel de (1972): «Nuestra egolatría de los del 98» (1916), Libros y autores españoles contemporáneos, Madrid, Espasa-Calpe, p. 133.

19 Jeschke, La generación de 1898, p. 73; SAlinas, «El concepto de generación», p. 26. Y le otorga el tercer lugar de la nómina, tras Unamuno y Azorín, Laín EnTRALGo, La generación del noventa y ocho, p 29.

${ }^{20}$ Recogido luego en Clásicos y modernos con el título «El paisaje en la poesía» (pp. 70-74). Hay que notar, no obstante, que en dicho artículo se reconoce la pertenencia de Machado a la generación de nuevos poetas, que no puede ser otra que la que bautizará el año siguiente como «del 98»: «Antonio Machado pertenece a un grupo de poetas venidos al arte en estos últimos años. [..] Lugar preeminente ocupa en esa generación nuestro poeta.» (p. 73). Diríase que se intuye la filiación novantayochista de Machado.

21 Azorín, «La generación de 1898», pp. 176-177. Análisis de la definición azoriniana de la generación del 98 en Fox, Edward Inman (1962): Azorín as a Literary Critic, Nueva York, Hispanic Institute in the United States, pp. 140-144. Aporta precisiones de interés sobre la gestación del concepto de generación del 98 en Azorín y sus tanteos designativos MARÍAs, Julián (1975): Literatura y generaciones, Madrid, Espasa-Calpe, pp. 133-138. 
un principio al margen de la generación del 98. Es más, incluso negó su pertenencia al grupo ya en sus últimos años, cuando era poco menos que un clásico. ${ }^{22}$

Sin embargo, entre ambos autores, los dos que encarnarían de modo más neto la esencia noventayochista, pronto se establecieron vínculos de amistad, ${ }^{23}$ una amistad que presentaba cierta asimetría en la medida en que Machado, desde su connatural humildad, otorgaba a Unamuno un papel magistral que va a condicionar una relación personal caracterizada por la mutua admiración. La iniciativa partió de Machado, que, a la vista de la generosa crítica que el eminente catedrático salmantino había dedicado al libro de su hermano Manuel Alma ${ }^{24}$ decidió dedicarle un ejemplar de Soledades (1903) con la siguiente dedicatoria: «A Don Miguel de Unamuno, al Sabio y al Poeta. Devotamente, Antonio Machado». Unamuno escribió un artículo en Helios (año I, vol. II, n. ${ }^{\circ}$ VIII, agosto de 1903), revista que recoge las voces de la nueva juventud literaria, en que comentaba la recién iniciada relación epistolar. Machado, por su parte, contestó con una carta abierta en El País, donde lo consideraba como «maestro». ${ }^{25}$ Es de notar que en torno a 1904, sólo él le reconocía a Unamuno una suerte de liderazgo, que los componentes del grupo «Los tres» no estaban dispuestos a concederle. ${ }^{26}$

\section{LA INSPIRACIÓN UNAMUNIANA DE CAMPOS DE CASTILLA}

Campos de Castilla (1912) representa la cima de la creación poética de Antonio Machado y su consagración como una de las voces líricas más vigorosas dentro del panorama literario español. Dentro de su itinerario poético traza un cambio de rumbo: el empeño de «encapsular lo eterno humano» en el poema imponía un desplazamiento desde los espacios cerrados de Soledades al espacio abierto al mundo. ${ }^{27}$ El azar llevó a Machado a Soria, ${ }^{28}$ donde descubrió el paisaje de Castilla. El andaluz que pasara su juventud en Madrid y París devino incondicional admirador del campo castellano. El castellanismo que adopta antes que apuntar a la exaltación idealizadora se torna clave de una interpretación crítica de la realidad española. A la elaboración del castellanismo

${ }^{22}$ En la entrevista concedida a La Voz de Madrid (1938), en que alega razones cronológicas y propias de su ingénita modestia, reconociendo su condición discipular con respecto a aquellos próceres de las letras [véase Albornoz, Aurora de (1968): La presencia de Miguel de Unamuno en Antonio Machado, Madrid, Gredos, p. 18].

${ }^{23}$ Es fundamental al respecto el estudio de Ribbans, Geoffrey, «Unamuno y Antonio Machado», Niebla y soledad, pp. 285-322. Véase asimismo Albornoz, La presencia, pp. 21-52.

${ }^{24}$ UnAmuno, Miguel de, «El «Alma» de Manuel Machado» (1901), Libros y autores, pp. 25-33.

${ }_{25}$ Gibson, Ian (2006): Ligero de equipaje. La vida de Antonio Machado, Madrid, Santillana, pp. 151153. Se reproduce el texto íntegro de la carta de Unamuno en Ribbans, «Unamuno y Antonio Machado», 289-292.

${ }^{26}$ RibBans, «Unamuno y ‘los jóvenes`», p. 77.

${ }_{27}$ Conforme a la penetrante interpretación de Gullón, Ricardo (1987): Espacios poéticos de Antonio Machado, Madrid, Fundación Juan March/Cátedra, p. 37. Se trata de un proceso similar al que por aquellos años lleva a Juan Ramón Jiménez del solipsismo que caracteriza su primera etapa a la apertura al mundo exterior que ya se observa en Diario de un poeta recién casado (1917, aunque el libro fue concluido en 1916). Sin embargo, hay que tener en cuenta que ya en Soledades se incoa esa apertura al mundo exterior en esos tanteos de descripción objetiva finamente analizados por Ribbans, Geoffrey, «Poesía temprana de Machado: Segunda etapa», Niebla y soledad, pp. 247-254. Este mismo autor señala la influencia de Unamuno en esa cambio de rumbo poético («Unamuno Y Antonio Machado», pp. 300-302).

${ }_{28}$ Para la etapa soriana del poeta véase GiBson, Ligero de equipaje, 2006, pp. 179-258. 
como eje en torno al cual se vertebra la reflexión sobre el tema de España dedicaron sus esfuerzos intelectuales Unamuno y Azorín. Se ha destacado una doble vertiente crítica en tales afanes reflexivos: por un lado era una forma de reacción ante la derrota en la guerra norteamericana; por otro, la reivindicación del terruño y del paisanaje era un modo de protestar frente a la España oficial, la de los políticos de retórica patriotera. ${ }^{29}$

La lectura que Machado hizo de En torno al casticismo (1895) fue un estímulo decisivo ${ }^{30}$ si no en el giro que supone el tránsito de los espacios interiores al espacio exterior, indudablemente en la forma de contemplar el paisaje castellano, en la asunción del castellanismo como clave interpretativa de la realidad española. Machado asimiló no sólo la concepción de la casta histórica castellana y de lo castellano que planteaba Unamuno, sino la forma de representar el paisaje. Diríase que los dos poemas que van tras el autorretrato que sirve de pórtico a Campos de Castilla contienen la expresión lírica del pensamiento unamuniano.

\section{El paisaje, el paisanaje}

En el segundo de los ensayos de En torno al casticismo («La casta histórica de Castilla»), tras delimitar el concepto de casta histórica y hacer un somero repaso del proceso histórico en virtud del cual Castilla alcanzó la hegemonía peninsular, Unamuno dedica la sección III a una exposición sobre el espacio físico castellano que, partiendo de consideraciones de carácter geográfico, deriva hacia una evocación lírica del paisaje, en que la prosa unamuniana revela una extraordinaria capacidad para la representación plástica, para la sugestión del efecto visual. Dicha exposición tiene la función de determinar los condicionamientos del medio natural sobre el hombre castellano, del que se traza un completo retrato. ${ }^{31}$

Unamuno expone el efecto del clima sobre el tapiz vegetal de Castilla, destacando la erosión que sufre la Meseta debido a aguaceros y nevadas, a los que se suman las sequías, que impiden que una vegetación fresca retenga la tierra. Es de notar que para la exposición del dato estrictamente geográfico se movilizan recursos expresivos que le confieren inequívoco carácter literario. ${ }^{32} \mathrm{El}$ uso del verbo «desollar» para referirse al efecto erosivo no es simple figura retórica, prosopopeya: el paisaje deviene ser vivo que es atormentado y sufre. Se sugiere, por tanto, una disposición contemplativa conforme a la cual se proyecta sobre el objeto contemplado el dolor del sujeto. Machado evoca asimismo los rigores de la erosión sobre el campo castellano, de la que hace testigo al «hombre de estos campos», que contempla su infortunio.

\footnotetext{
${ }^{29}$ Gullón, Espacios poéticos, pp. 35-36.

30 Se ha señalado simplemente que «le había influido», pero sin analizarse en qué grado y de qué modo [SEsÉ, Bernard (1990): Claves de Antonio Machado, Madrid, Espasa-Calpe, p. 109].

31 Unamuno, Miguel de (1972): En torno al casticismo (1895), Madrid, Espasa-Calpe, pp. 51-59. Destaca la orientación positivista del pensamiento de Unamuno cuando redactó esta obra como clave esencial de la misma JuARIsti, Jon (2013), «Unamuno. Casticismo e intrahistoria», Espaciosa y triste. Ensayos sobre España, Madrid, Espasa, pp. 203-205.

32 «Los grandes aguaceros y nevadas descargando en sus sierras y precipitándose desde ellas por los empinados ríos, han ido desollando sigo tras siglo el terrero de la meseta...» (UNAMUNO, En torno al casticismo, p. 52).
} 
Hoy ve [el hombre de estos campos] a sus pobres hijos huyendo de sus lares;

la tempestad llevarse los limos de la tierra

por los sagrados ríos hacia los anchos mares. ${ }^{33}$

El paisaje castellano no podía ser placentero. Unamuno, precisamente tras exaltar la belleza de una puesta de sol en la inmensidad de la llanura castellana, observa lo ajeno de las tierras castellanas al sentimiento voluptuoso. Este paisaje ni invita al goce ni es acogedor. El vasco que ha gozado de los campos verdes añora en Castilla la elemental fruición a que éstos incitan. ${ }^{34}$ Esa misma caracterización mediante negación del opuesto aparece en la evocación de llanuras y páramos en Machado, sólo que adquiere un espléndido desarrollo. El campo verde se torna «bíblico jardín» y la referencia veterotestamental, por asociación de opuestos, atrae el fratricidio cainita, que se alza como hado fatal de España y sirve de espléndido cierre al poema «Por tierras de España»:

Veréis llanuras bélicas y páramos de asceta

-no fue por estos campos el bíblico jardín-:

son tierras para el águila, un trozo de planeta

por donde cruza errante la sombra de Caín. ${ }^{35}$

La evocación del arbolado castellano ${ }^{36}$ presenta asimismo cierta analogía que no ha de ser enteramente trivial por mera identidad de la realidad descrita. En efecto, ambos autores habían de referirse a encinas y álamos, mas la preeminencia que otorga Machado a ambos árboles en la pintura del paisaje castellano encuentra un significativo antecedente en Unamuno, quien, tras referirse al atormentado relieve de Castilla, expone las peculiaridades del tapiz vegetal: campos de cereal, arbolado y matorral. La enumeración de los árboles característicos del paisaje castellano se hace en clave lírica: los epítetos destacan las notas esenciales. ${ }^{37}$ Machado, por su parte, dedica un poema a la encina («Las encinas»), situado tras las amplias panorámicas del campo castellano y la caracterización del hombre que lo puebla. Ya la selección es elocuente. Cuando evoque con irreprimible nostalgia la tierra castellana desde su Andalucía natal, la asociará a la encina. ${ }^{38}$ No ha de ser casual que el epíteto asignado por Unamuno a las encinas será el

${ }^{33}$ Machado, Antonio (1979): Campos de Castilla, Poesías completas, ed. M. Alvar, Madrid, EspasaCalpe, p. 139. Se ha señalado la filiación de las observaciones de Machado sobre el campo castellano con las preocupaciones de los ilustrados por la cuestión agraria [Predmore, Michael (1981): Una España joven en la poesía de Antonio Machado, Madrid, Ínsula, pp. 127-128]. Estimamos, empero, más directa la relación con las reflexiones de Unamuno.

34 «No despierta este paisaje sentimientos voluptuosos de alegría de vivir, ni sugiere sensaciones de comodidad y holgura concupiscibles; no es un campo verde y graso en que den ganas de revolcarse, ni hay repliegues de tierra que llamen como un nido.» (En torno al casticismo, p. 54).

35 Campos de Castilla, p. 140.

${ }^{36}$ Se ha señalado la importancia de los árboles en los paisajes de Unamuno [DE LA CALzADA, Jerónimo (1952): «Unamuno paisajista», Cuadernos de la Cátedra Miguel de Unamuno, III, pp. 71-72]. Véase asimismo Albornoz, La presencia, pp. 156-157.

37 «pardas encinas», «tristes pinos». Los álamos, en cambio, carecen de epíteto (En torno al casticismo, p. 53). Es de notar cómo en un poema dedicado precisamente a las encinas castellanas, Unamuno les confiere una dimensión histórica: «Sobre este mar que guarda en sus entrañas/ de toda la tradición el manadero/ esperan una voz de hondo conjuro/ largos silencios.» [UNAMUNo, Miguel de (1987): «El mar de encinas» (1906), Poesía completa (1), Madrid, Alianza Editorial, p. 62].

38 «hermosa tierra de encinar»: tal es la perífrasis con que nombra a Castilla en «Olivo del camino» [Nuevas canciones (1917-1930), Poesías completas, p. 249]. Destaca, por su parte, la dimensión «nacional» 
que prefiera Machado en el poema de Campos de Castilla: «pardas» se repite frente a «negra» $\mathrm{y}$ «campesina», sólo una vez utilizados. ${ }^{39}$

Los álamos, a su vez, para Unamuno «adquieren vida intensa y profunda». ${ }^{40}$ ¿No habrá que ver en la estampa de los álamos de la ribera del Duero, entre san Polo y san Saturio, ${ }^{41}$ el desarrollo de la intuición unamuniana? El chopo testigo de amores se torna emblema de los enamorados. $\mathrm{Y}$ en la medida en que el poeta reconoce que pasan a formar parte de lo más íntimo de su persona, ${ }^{42}$ ¿no están adquiriendo una vida intensa?

El paisaje machadiano se humaniza en la medida en que aparece poblado del paisanaje. La perspectiva es doble: en un primer plano aparece el retrato implacable; en un plano general figuras contempladas en lontananza. Unamuno evoca a los hombres del campo castellano, a los labriegos como figuras que se recortan en el paisaje. Resulta sumamente significativo que la exposición sobre el poblamiento de Castilla se escore hacia la efusión lírica. Precisamente el momento de expresión más intensa, en que el sesudo ensayista prorrumpe en emotiva exclamación, es la evocación de labriegos y gañanes sobre el telón de fondo de la gleba castellana. ${ }^{43}$ La mirada de Machado adopta análogo enfoque. Ya en la espléndida obertura castellanista del poemario, en «A orillas del Duero», se representa el paisanaje subrayándose la distancia propia del plano general, a la vez que se convoca, al igual que Unamuno, a hombres montados en caballerías:

[Veía] y, silenciosamente, lejanos pasajeros,

¡tan diminutos! -carros, jinetes y arrieros-,

cruzar el largo puente...44

Una expresión más elaborada de esa visión en lontananza de los hombres del campo castellano presenta la estampa tercera de «Campos de Soria»: labriegos montados en sus caballerías al atardecer. Mas en este caso Machado recurre a la paleta pictórica modernista, con sus fulgores dorados, que contrastan con las habituales gamas grises, pardas, para destacar a los personajes captados como en escena cinematográfica, pues se sugiere el movimiento de esos viajeros que quedan ocultos por los accidentes del terreno y reaparecen de nuevo. «Plebeyas figurillas»: nunca tan certero el diminutivo, que acumula tanto el dato objetivo de la mirada distante como la estimación afectiva.

\footnotetext{
de este poema y su naturaleza noventayochista SÁnchez BARBudo, Antonio (1981): Los poemas de Antonio Machado. Los temas. El sentimiento y la expresión, 4. a ed., Barcelona, Lumen, p. 195.

39 «Las encinas», pp. 144, 145 y 146. Se ha señalado, no obstante, la mayor riqueza cromática de Machado frente a Unamuno (AlBORNOZ, La presencia, pp. 151-152.

${ }^{40}$ En torno al casticismo, p. 53.

41 «Campos de Soria», Campos de Castilla, pp. 157-159.

42 «[...] álamos de las márgenes del Duero,/ conmigo vais, mi corazón os lleva!» («Campos de Soria», p. 159). El apóstrofe, en tanto que interpelación, es factor vivificador por excelencia.

${ }^{43}$ « $_{\text {Y }}$ que es de ver verlos a la caída de la tarde, bajo el cielo blanco, dibujar en él sus siluetas, montados en sus mulas, dando al aire sutil sus cantares lentos, monótonos y tristes, que se pierden en la infinita inmensidad del campo lleno de surcos!» (En torno al casticismo, p. 56). Y es que Unamuno estudia el paisaje castellano por considerarlo factor importante en la formación del carácter castellano [CARDIs, Marianne (1953): «El paisaje en la vida y en la obra de Miguel de Unamuno», Cuadernos de la Cátedra Miguel de Unamuno, IV, p. 79].

${ }^{44}$ «A orillas del Duero», Campos de Castilla, p. 138. Para Unamuno el labriego montado en su mula viene a ser la estampa típica del paisanaje castellano, una suerte de símbolo (En torno al casticismo, p. 56).
} 
Es el campo undulado, y los caminos

ya ocultan los viajeros que cabalgan

en pardos borriquillos,

ya al fondo de la tarde arrebolada

elevan las plebeyas figurillas,

que el lienzo de oro del ocaso manchan. ${ }^{45}$

La sensibilidad social de Machado se revela en el adjetivo «plebeyas». Al estímulo puramente visual, a la captación de las cualidades plásticas de la estampa, sucede la indagación en la vida del paisanaje a través de una historia o, mejor, de un esbozo de narración. La evocación de las «figurillas» parece exigir del poeta un desarrollo más demorado. De ahí que el cuadro siguiente se inicie con una exclamación que expresa la fascinación por el componente humano de la representación paisajística. Y he aquí la estampa de un matrimonio con su hijo: el marido guiando la yunta que abre en la tierra los surcos para la siembra, la mujer echando la semilla, el niño en un cesto que cuelga del pesado yugo. Una familia que trabaja «sudando sobre la dura tierra ${ }^{46}$ constituiría la sólita historia del paisanaje castellano. Así, la apelación al sudor, como expresión metonímica del duro trabajo del campo, se torna enternecedora historia.

Unamuno ofrece un esbozo de retrato del hombre castellano, que resulta modelado por los rigores de un clima inclemente: complexión seca y dura, sobriedad y austeridad. ${ }^{47}$ En este punto, el determinismo geográfico se lleva al extremo: los rasgos enumerados son el resultado de la selección que heladas y penurias han llevado a cabo. Darwinismo y determinismo se aúnan en el esfuerzo que hace Unamuno por ofrecer un fundamento científico a la idiosincrasia del hombre castellano. ${ }^{48} \mathrm{Y}$ sin embargo, a los largo de los años, evolucionará hacia un planteamiento más espiritual, en el que se antepone una dimensión trascendente a la identidad nacional. ${ }^{49}$

45 «Campos de Soria», p. 155. Con fina sensibilidad se ha comparado la visión de las figurillas con «un exquisito viejo cuadro japonés» (SÁnCHEZ BARBUdo, Los poemas, p. 182).

${ }^{46}$ En torno al casticismo, p. 56. No hay que perder de vista que Unamuno «cimenta la historia sobre el protagonismo popular» [Tữón DE LARA, Manuel (1986): España: la quiebra de 1898, Madrid, Sarpe, p. 148].

47 «Allí dentro vive una casta de complexión seca, dura y sarmentosa, tostada por el sol y curtida por el frío, una casta de hombres sobrios, producto de una larga selección por las heladas de crudísimos inviernos y una serie de penurias periódicas, hechos a la inclemencia del cielo y a la pobreza de la vida.» (En torno al casticismo, p. 56). Diríase que más que de la observación directa de la realidad, este vigoroso retrato del hombre castellano deriva del recuerdo de la lectura de Justino (historiador del siglo II o III), quien, al extractar a Trogo Pompeyo, dejó una semblanza de los hispanos que se erigiría en canónica: «Corpora hominum ad inediam laboremque, animi ad mortem parati. Dura omnibus et adstricta parsimonia.» (Justino, Epítome, XLIV, 2, 1).

${ }^{48}$ Se ha señalado que por estos años Unamuno participaba de la creencia en primitivos sustratos raciales y culturales que, en función del medio geográfico, determinarían comportamientos atávicos de la sociedad, contribuyendo de este modo a la ideología del nacionalismo vasco. Tal visión positivista se fundamentaba en Spencer, Taine, Wundt, divulgador este último de la Völkerpsychologie [JUARISTI, Jon (2000): El bucle melancólico. Historias de nacionalistas vascos, Madrid, Espasa-Calpe, p. 111]. Conviene constatar que por aquellas calendas, frente al determinismo de que hacía gala Unamuno para caracterizar la «casta española», un historiador profesional, limitaba los condicionamientos geográficos sobre la «psicología del pueblo español: «... la personalidad nacional y patriótica no depende tan por completo del suelo como se ha creído, sino, ante todo y sobre todo, de la existencia de un espíritu común en el grupo...» [Altamira, Rafael (1998): Psicología del pueblo español (1917), Madrid, Biblioteca Nueva, p. 70. La primera edición de esta obra apareció en 1902].

${ }_{49}$ Sumamente reveladora es la siguiente observación: «Paisano es el del país, el del pago, el hombre natural, de Dios, que se hace luego nacional, histórico, más humano y más de Dios.» [UnAmuno, Miguel 
Machado parece asumir el planteamiento unamuniano de la determinación del carácter por el medio natural, suelo y clima, al situar el poema en que traza un retrato implacable del hombre del campo castellano, «Por tierras de España», tras la espléndida introducción que presenta, como en una gran obertura, los temas principales de Campos de Castilla. La contigüidad vendría a sugerir una relación de causa y efecto. De hecho, se establece una vinculación entre tierra y carácter, aunque ciertamente queda limitada por la expresión metafórica. ${ }^{50}$ Ahora bien, Machado añade al planteo de Unamuno la determinación de la historia. El hombre castellano ya no es tanto «producto» de un clima de rigor despiadado, sino «hijo de una estirpe de rudos caminantes». La dimensión histórica viene dada por el contraste entre los adverbios «antaño» $\mathrm{y}$ «hoy», un pasado caracterizado por la afanosa roturación y un presente de resignación ante las adversidades de un clima que obliga a la emigración. La tierra antaño ganada al cultivo ya no son sino «páramos malditos»: la maldición aludida adquiere resonancias bíblicas merced a las referencias veterotestamentales con que se cierra el poema. ${ }^{51}$ La historia que se plantea no es, pues, sino la de una decadencia.

La caracterización esbozada por Unamuno adquiere un desarrollo completo: diríase que la inspiración libresca, erudita, ha sido sustituida por la observación directa de la realidad. El resultado es un retrato implacable alejado de toda idealización popularista.

Pequeño, ágil, sufrido, los ojos de hombre astuto,

hundidos, recelosos, movibles; y trazadas

cual arco de ballesta, en el semblante enjuto

de pómulos salientes, las cejas muy pobladas.

Abunda el hombre malo del campo y de la aldea,

capaz de insanos vicios y crímenes bestiales,

que bajo al pardo sayo esconde un alma fea

esclava de los siete pecados capitales. ${ }^{52}$

La descripción se centra en el rostro, como si obedeciera a la creencia popular de que la cara es el espejo del alma, de manera que el rasgo físico se combina de modo inextricable con la caracterización moral. En lugar preeminente la capacidad para sufrir con entereza las adversidades. A partir de ahí, Machado desarrolla libremente su visión del paisanaje castellano. Sin concesión alguna a idealizaciones popularistas, destaca el

de (1997): «Manzanares arriba, o las dos barajas de Dios» (1932-1933), Paisajes del alma, Madrid, Alianza Editorial, p. 149]. Asimismo, por aquellas fechas, Ganivet, amigo entrañable de Unamuno, al hilo de sus reflexiones sobre el espíritu español, identificaría «el elemento moral» y «religioso más profundo» de España con «el estoicismo natural y humano de Séneca» [GANIVET, Ángel (1999): Idearium español (1897), ed. E. Inman Fox, Madrid, Espasa-Calpe, pp. 45-46].

${ }^{50}$ «El numen de estos campos es sanguinario y fiero...» («Por tierras de España», Campos de Castilla, p. 139).

51 Ya Machado destacó la importancia de la inspiración bíblica, veterotestamental, de Campos de Castilla: «... mis romances miran a lo elemental humano, al campo de Castilla y al libro primero de Moisés, llamado Génesis.» [Prólogo a Campos de Castilla (1917), Poesías completas, p. 69].

52 «Por tierras de España», p. 139. Se ha observado que también Unamuno ya se había referido a crímenes «más propios de bestias» (Albornoz, La presencia, p. 184). Se atribuyeron tales conductas criminales a degeneración de la raza, en el marco de las reflexiones sobre la decadencia nacional. Era un tema que suscitaba entonces un gran interés [PÉrez, Joseph (2012): La leyenda negra, Gadir, Madrid, pp. 200-201]. 
recelo y la astucia como cualidades esenciales del hombre del campo castellano, ${ }^{53}$ a la vez que no oculta su faceta más turbia: insanos vicios y crímenes bestiales. Envidia y violencia cierran este retrato despiadado. Así, el esbozo de Unamuno, centrado en el carácter sobrio y sufrido del hombre castellano, adquiere un desarrollo completo, presidido por una intención crítica, ${ }^{54}$ conforme a la cual se hace una disección de su alma, que descubre una realidad cruda.

Ciertamente, Machado no se mostró nada indulgente en la estimación del hombre castellano, que contrasta notablemente con el entusiasmo sin reservas que exhibe ante el paisaje. Llama la atención que el hijo del folclorista Demófilo, que le enseñó a leer en el Romancero, ${ }^{55}$ muestre tal desapego hacia el paisanaje de Castilla. Tal vez el desencanto sentido ante la realidad con que el azar le puso en contacto esté en la base de tan inmisericorde visión. Así se explicaría ese verso en el que se despoja al hombre castellano de todo encanto folclórico: «y atónitos palurdos sin danzas ni canciones». ${ }^{56}$ Tal vez quien esperara tesoros de arte popular por esos campos de Soria se encontró con un vacío que supuso una decepción. Frustración ante las expectativas generadas: tal es el sentimiento que desprende la implacable estimación contenida en dicho verso.

\section{La visión de la historia}

En su lectura de En torno al casticismo, Machado se revelaría especialmente receptivo en lo que respecta a la visión de la historia allí planteada. Los ensayos de Unamuno se sitúan en el marco de la abigarrada literatura surgida en la crisis de conciencia finisecular. ${ }^{57}$ El título del que cierra la serie que compone el libro no puede ser más significativo: «Sobre el marasmo actual de España». Las «errabundas pesquisas en torno al casticismo» apuntan a reflexionar sobre la «honda crisis» por que atraviesa España, pues en ella «persisten y se revelan en la vieja casta los caracteres castizos». ${ }^{58} \mathrm{Y}$ el casticismo se manifiesta al observador en la historia: «Para llegar, lo mismo un pueblo que un hombre, a conocerse, tiene que estudiar de un modo o de otro su historia.» ${ }^{59} \mathrm{La}$ indagación en el pasado, pues, venía exigida como requisito para abordar el diagnóstico de la crisis. Machado asimiló profundamente ese imperativo de conocimiento histórico,

\footnotetext{
${ }^{53}$ Se trata de una observación hondamente arraigada en la estimación de Machado, pues reaparece al caracterizar a esos «trajinantes y arrieros/ de ojos inquietos, de mirar astuto» que forman parte del paisanaje castellano («Desde mi rincón», Campos de Castilla, p. 238).

${ }^{54}$ Se ha sugerido el carácter apocalíptico de tal visión crítica. Resulta, empero, excesivo apelar a «principios satánicos» (Predmore, Una España joven, p. 134) para interpretar lo que no es sino referencia al vicio hispánico por excelencia.

55 Sobre el padre y la infancia de Machado véase GIBSon, Ligero de equipaje, pp. 39-57.

56 «A orillas del Duero», p. 138.

${ }^{57}$ Dicha crisis no es fenómeno exclusivamente español, sino manifestación de una más amplia que afecta a la identidad nacional europea (IGLESIAS, Carmen (2008): «Fines de siglo y sentimiento de crisis. 1898: Imágenes u realidad», No siempre lo peor es cierto, Barcelona, Galaxia Gutenberg, pp. 591-594). Ya lo había advertido con severo tono crítico AzAÑA, Manuel (2002) «¡Todavía el 98!», Plumas y palabras (1930), Barcelona, Crítica, p. 179.

${ }^{58}$ En torno al casticismo, p. 127. Asimismo, se exige que el estudio de la historia sea «un implacable examen de conciencia» (p. 35).

59 En torno al casticismo, p.39.
} 
que le llevará a otorgar una dimensión temporal al paisaje, de manera que se erige en representación del pasado.

\section{2.a. Castilla, España}

En su indagación sobre la esencia del pueblo español, Unamuno toma como punto de partida la realidad espiritual, frente a cualquier planteamiento basado en criterios raciales. De ahí que escoja el término «casta» como categoría sobre la que fundamentar la identidad hispana. Pues bien, si en la lengua se manifiesta el sentir y el pensar de un pueblo, había que colegir, por tanto, que «en la literatura española, escrita y pensada en castellano, lo castizo, lo verdaderamente castizo, es lo de vieja cepa castellana.» Y a renglón seguido se afirma que «Castilla ha hecho la nación española». ${ }^{60} \mathrm{La}$ idea de Castilla forjadora de España constituye uno de las convicciones de Machado que está en la base de su visión de la realidad castellana.

Y en efecto, más que como desarrollo explícito, esta idea aparece como una tácita asunción en virtud de la cual adquieren pleno sentido otros planteamientos o temas. No es de extrañar, por tanto, que cuando se formule expresamente, se trate de un enunciado secundario, como de algo consabido. Así, en el poema «Las encinas», en la evocación de aquellas regiones españolas donde crece este árbol, la mención de Castilla incluye una aposición que contiene la idea en cuestión. ${ }^{61}$ Asimismo, como supuesto que otorga pleno sentido al poema está presente en «Desde mi rincón», dedicado a Azorín con motivo de la publicación de su libro Castilla (1912). Ya al comienzo del poema se plantea la identificación entre Castilla y España, muy significativamente tras invocar a ambas Castillas. ${ }^{62}$ En la medida en que el poema, con su evocación de los hitos literarios privilegiados (el Arcipreste de Hita, La Celestina, el Quijote), posee una dimensión histórica, esa identificación sólo se entiende en tanto que Castilla ha forjado a España. Las observaciones sobre la Castilla representada en el libro se trasponen a España. ${ }^{63}$ Por otra parte, las consideraciones que cierran la primera parte («Elogios») se refiere a la España actual. La evocación lírica de Castilla es sustituida por una crítica implacable desde la que se vislumbra un futuro que se ha de construir sobre la firme creencia en la libertad, la esperanza y la fe. ${ }^{64}$

En «A orillas del Duero» la idea se presenta como presupuesto que da sentido a la evocación histórica que sirve para patentizar la decadencia actual. Sin solución de continuidad se pasa de la historia propiamente castellana, la de las gestas cidianas, a la de España, conquista de América. De ahí que se salte de la referencia a Castilla a la de España. ${ }^{65}$ Aun más explícita es la identificación entre Castilla y España en «Por tierras

\footnotetext{
${ }^{60}$ En torno al casticismo, p. 44.

61 «encinas de Extremadura,/ de Castilla, que hizo a España...» («Las encinas», p. 146).

62 « Castilla, España de los largos ríos...» («Desde mi rincón», p. 238).

${ }^{63}$ « Y este filtrar la gran hipocondría/ de España siglo a siglo y gota a gota!» («Desde mi rincón», p. 239).

${ }^{64}$ Curiosa variación de las virtudes teologales («Desde mi rincón», p. 239)

${ }^{65}$ «... soldados,/ guerreros y adalides que han de tornar cargados/ de plata y oro, a España...» («A orillas del Duero», p. 138).
} 
de España». El deíctico del primer verso sitúa el poema en Castilla. ${ }^{66}$ Mas la crítica implacable no es sólo del hombre castellano, sino del español.

\section{2.b. Castilla: mística y guerrera}

En el ensayo titulado «De mística y humanismo», Unamuno parte de la convicción de que la «filosofía de un pueblo» suele ser la «teoría justificativa de su modo de ser», el «reflejo del ideal que de sí mismo tiene». Pues bien, halla que el espíritu castellano tomó por «filosofía castiza la mística», lo cual explica en virtud de la naturaleza guerrera de la casta castellana, mal avenida al trabajo y a interrogar la realidad por la vía del método científico y que, por el contrario, aspiraba a conquistar la verdad suprema «por gracia de la contemplación». No la ciencia, pues, sino la mística viene a ser la filosofía propia del espíritu castellano. ${ }^{67}$ La contigüidad que en Machado se observa en las facetas mística y guerrera de su caracterización de Castilla revela su deuda con las reflexiones de Unamuno sobre la visión del mundo que atribuye a la casta castellana.

La idea cristaliza en espléndida acuñación verbal: los epítetos «mística y guerrera». Aparecen en primer lugar para enfatizar el apóstrofe dirigido a esas tardes de Soria evocadas con tristeza y amor. ${ }^{68}$ Soria representa para el poeta la manifestación más aquilatada de Castilla. El contraste entre la serie de epítetos con que por tres veces se apostrofa a Castilla con la ausencia de ellos para referirse a Andalucía revela la distancia afectiva: del recuerdo emocionado a la inevitable resignación.

-yo tuve patria $[\ldots]$

allá en Castilla, mística y guerrera,

Castilla la gentil, humilde y brava,

Castilla del desdén y de la fuerza-,

En estos campos de mi Andalucía,

¡oh tierra en que nací!, cantar quisiera. ${ }^{69}$

Mas el desarrollo de la idea ya había aparecido en «A orillas del Duero». Esos «filósofos nutridos de sopa de convento» han de entenderse referidos a los místicos para que cobre sentido cabal la amplia panorámica histórica que se ofrece en este poema. La locución, sumamente expresiva por la nota realista de la «sopa de convento», que, más que connotar privaciones ascéticas, sugiere una pobreza sórdida, sólo se entiende plenamente si se tiene en cuenta que el misticismo era para Unamuno la filosofía de la casta castellana. Sus cultores eran, pues, frailes, hombres de claustro conventual. No se trata, pues, de una crítica de la tradición filosófica hispana a la que se achaque hegemonía clerical. A su vez, el verbo que se refiere a su quehacer viene a confirmar la índole mística de tales filósofos. Contemplar constituye el término sobre el que pivota la exposición unamuniana del conocimiento místico: la conquista de una verdad suma «por gracia

${ }^{66}$ «El hombre de estos campos...» («Por tierras de España», p. 139).

${ }^{67}$ En torno al casticismo, pp. 101-103.

68 «tardes de Soria, mística y guerrera» («Campos de Soria», p. 157).

69 «Caminos», Campos de Castilla, p. 198. 
de contemplación». ${ }^{70}$ Los versos adquieren una densidad conceptual realzada por una expresión de acerada precisión:

Filósofos nutridos de sopa de convento

contemplan impasibles el amplio firmamento;

y si les llega en sueños, como un rumor distante,

clamor de mercaderes de muelles de Levante,

no acudirán siquiera a preguntar: ¿qué pasa? $?^{71}$

El contexto asimismo corrobora la inspiración unamuniana del tipo histórico aquí invocado. Para Unamuno, el misticismo es propio de la casta «castellana de conquistadores, mal avenidos al trabajo». ${ }^{72} \mathrm{Y}$ precisamente los «filósofos» figuran en el poema a continuación de la referencia a la conquista de América, de la evocación de la figura del «conquistador». La contigüidad en el poema de conquistadores y místicos constituiría la expresión lírica de la relación que establece Unamuno entre ambos tipos humanos.

Asimismo, que sobre la imagen de la historia hispana que presenta Machado en este poema gravitaba el recuerdo de su lectura de En torno al casticismo viene avalado por diversas coincidencias entre el poema y el ensayo. En primer lugar, la espléndida referencia a un pasado en el que se combatía por la religión, que para Unamuno constituía un vínculo social esencial.

[...] Sobre sus campos aún el fantasma yerra

de un pueblo que ponía a Dios sobre la guerra. ${ }^{73}$

Unamuno desarrolló sus consideraciones sobre la religiosidad guerrera de la casta castellana en el apartado V (el último) del ensayo «El espíritu castellano», que precede y anuncia a «De mística y humanismo». ${ }^{74}$ Hay que suponer una lectura penetrante, sumamente reflexiva, por parte de Machado, en la medida en que asimiló plenamente los planteamientos de Unamuno. No sólo en la idea general, sino en el detalle cabe observar el resultado de dicha lectura. El rasgo con que aparece dibujado el Cid en «A orillas del Duero» es, además de la fidelidad inquebrantable al rey Alfonso, que se manifiesta en los regalos que le ofreciera, la satisfacción por las riquezas conseguidas.

cuando Myo Cid Rodrigo el de Vivar volvía,

ufano de su nueva fortuna y su opulencia,

a regalar a Alfonso los huertos de Valencia... ${ }^{75}$

${ }^{70}$ En torno al casticismo, p. 102. Ciertamente, para Unamuno, la mística castellana «arranca del conocimiento introspectivo de sí mismo, cerrando los ojos a lo sensible» (p. 103). Mas en términos de expresión lírica, el objeto de esa conquista espiritual, «una verdad suma», requería una referencia más concreta: ¿qué mejor que el firmamento?

71 «A orillas del Duero», p. 138. No se trata, pues, de «eco de una vieja visión romántica de España» (SÁnchez BARbudo, Los poemas, p. 184), sino de eco de la lectura de la reciente reflexión sobre el tema de España.

${ }^{72}$ En torno al casticismo, p. 102.

73 «A orillas del Duero», p. 138. Cfr.: «Que las castizas guerras de nuestra edad de oro fueron de religión... Ésta era el lazo social, y la unidad religiosa, forma suprema de la social.» (En torno al casticismo, p. 94).

${ }^{74}$ Así, su último párrafo enuncia la tesis que se desarrollará en el ensayo siguiente: «En ninguna revelación del alma castellana que no sea su mística se entra más dentro en ella...» (En torno al casticismo, p. 97).

75 «A orillas del Duero», p. 138. 
Extraña que, al tratar de uno de los más egregios representantes de esa casta de guerreros y conquistadores, se silencien las cualidades propiamente bélicas, ofreciéndose una curiosa perspectiva épica: el Cid haciendo balance de los beneficios obtenidos tras la conquista de Valencia. Precisamente al tratar de la belicosa religiosidad de los castellanos, Unamuno hacía una breve digresión para mostrar cómo durante la Reconquista no había interés alguno en convertir a los moros y comparaba el Cantar de Mío Cid con la épica francesa, en la que los francos aparecen empeñados en la destrucción del islam mediante conversiones forzosas. Pues bien, la cita del Cantar que se incluye destaca precisamente el fabuloso enriquecimiento de quienes conquistaron Valencia. ${ }^{76}$

Así pues, la acuñación verbal de la pareja de epítetos mística y guerrera, referidos tanto a Soria como a Castilla, puede considerarse como la expresión lírica de una visión de la historia deudora de las apasionadas cogitaciones de Unamuno sobre el tema de España. De este modo tales epítetos no son sólo vehículo de la efusión lírica en que se manifiesta el vínculo afectivo del poeta con la tierra castellana, con su dilecta Soria, sino resultado de una reflexión sobre la realidad castellana en que convergen la observación atenta y sensible del paisaje y la meditada lectura de uno de sus autores más admirados, de manera que el paisaje adquiere una dimensión temporal, histórica, pues no sólo es escenario del paisanaje, sino testimonio vivo del pasado. ${ }^{77}$

\section{UN ECO DE CAMPOS DE CASTILLA EN UNAMUNO.}

Un paisajista tan sensible como Unamuno difícilmente podía sustraerse al encanto de Campos de Castilla. Aunque compuso algunos poemas de carácter paisajístico, ${ }^{78}$ parece preferir la prosa para representar el paisaje español, de que dejó vigorosas estampas en Andanzas y visiones españolas. Precisamente será en su prosa viajera y paisajística donde germine el recuerdo fecundo de la lectura de la obra de Machado.

En París, donde se estableció tras escaparse del destierro de Fuerteventura, Unamuno continuó su labor literaria, alternando proyectos como el que cuajó en La agonía del cristianismo con su infatigable producción epistolar. Hallaría asimismo espacio para el género viajero -Unamuno era un entusiasta de la literatura de viajes. ${ }^{79}$ El artículo «Salamanca en París» conjuga el interés por los nuevos lugares, la necesidad de dejar constancia de su presencia en ellos, con la evocación nostálgica de la tierra de que tuvo que partir hacia el exilio, de su entrañable Salamanca.

El punto de partida es la experiencia inmediata del transterrado. El deíctico con que se inicia el texto acerca al lector al lugar que va a describir, lo sitúa junto al autor, para que lo acompañe en su recorrido por el espacio descrito y atienda sus palabras. Un pe-

\footnotetext{
${ }^{76}$ En torno al casticismo, pp. 94-95.

77 De ahí que se haya afirmado que Machado vio en el paisaje el alma colectiva y secular (VALVERDE, José María (1986) Antonio Machado, 5. a ed., Madrid, Siglo XXI, pp. 93-94).

${ }^{78}$ Los dedicados a Castilla, Cataluña y Vizcaya [Unamuno, Poesía completa (1), pp. 61-96]. Prosa y verso llegan a unirse en el recuerdo nostálgico de la tierra entrañable hecho desde el destierro en «"Soñadero feliz de mi costumbre"» (Paisajes del alma, p. 91).

${ }^{79}$ Así, puesto en el trance de filosofar sobre la historia, afirmaba que mayor enseñanza se sacaba de los libros de viajes que de los de historia (En torno al casticismo, p. 33).
} 
queño y recoleto parque parisino cerca de la pensión donde se alojaba Unamuno, la plaza de los Estados Unidos, que le sirve de estímulo para el ejercicio de la nostalgia:

A este parquecito suelo bajar, enteramente solo -pero ¡con qué compañía dentro!-, cuando quiero arar y binar mi soledad parisiense, cuando quiero heñir mi morriña, o amasar mi nostalgia, si es que así lo creéis más claro por menos español. ${ }^{80}$

El parquecito parisino le aviva el recuerdo del salmantino Campo de San Francisco. El sueño viene a ser la vía que une ambos espacios. A través del sueño el lector pasa del «allí» que se refiere al parque parisino al «allí» que señala al salmantino. ${ }^{81}$ Desde el momento en que pasa a referirse a éste, aparece con lírica recurrencia, con cadencia anafórica que va marcando las notas asociadas a la experiencia vital de Unamuno. El ex-rector salmantino evoca los paseos por el campo franciscano, guiado por su amigo Cándido Pinilla, ciego, lo que de pie para articular una de sus dilectas paradojas: el invidente hace las veces de lazarillo del vidente.

Tras la espléndida descripción de la capilla barroca de la Veracruz y su enlace con la reflexión, más bien efusión sentimental, a propósito del otoño vital, de repente, el autor se dirige a su fraternal Cándido, a quien remite la nostálgica evocación del otoño salmantino. Pues bien, esa inflexión en la estructura comunicativa del texto cabe suponerla condicionada por el recuerdo del poema que Machado dedicó a su íntimo amigo José María Palacio, incluido en la segunda edición de Campos de Castilla, que le sugirió el procedimiento para la articulación lírica del recuerdo de la tierra en que ha vivido las experiencias más entrañables.

La estructura pragmática de ambos textos es prácticamente idéntica. Tanto el poeta como el articulista se hallan en tierra extraña -en el caso de Machado, habría que precisar que desde el punto de vista emocional-, exiliados del lugar al que el azar los llevó y con el que se identificarían plenamente. En ambos la evocación de la tierra añorada se articula en torno a la interpelación del amigo, a quien se apostrofa como si se tratara de confirmar la exactitud del emocionado recuerdo. El apóstrofe contiene cual epíteto el vínculo amical; ${ }^{82}$ en Machado aparece exento, haciendo las veces de salutación epistolar, ${ }^{83}$ mientras que en Unamuno se integra en la evocación del lugar.

Ambos evocan la manifestación de una estación del año en el paisaje dilecto, esto es, ofrecen no una estampa estática, sino el proceso por el que aquél adquiere vida. El poeta, la primavera; el articulista, el otoño. Dos estaciones diferentes pero que sirven de marco emocional a sendas situaciones vitales teñidas por la melancolía: la que destila la contenida emoción de la ofrenda floral a la tumba de la esposa amada del poeta, la

${ }^{80}$ Unamuno, Miguel de, «Salamanca en París» (1924), Paisajes del alma, p. 82. Acerca de la experiencia personal de Unamuno en París, se ha señalado que «tuvo que esforzarse por no sucumbir a la murria.» [JUARISTI, Jon (2012): Miguel de Unamuno, Madrid, Taurus, p. 368].

${ }^{81}$ El mismo adverbio tiene ambos referentes («Salamanca en París», p. 82).

82 «Palacio, buen amigo» (MACHADo, «A José María Palacio», Campos de Castilla, p. 199); «amigo Cándido», «querido Cándido» («Salamanca en París», p. 84). Ofrece un profundo y fino análisis de la amistad como vínculo que genera el diálogo que se establece con la interpelación GuILLÉn, Claudio (1989): «Estilística del silencio (en torno a un poema de Antonio Machado)», Teorías de la historia literaria, Madrid, Espasa Calpe, pp. 34-39

${ }_{83}$ De hecho se ha señalado la naturaleza epistolar de este poema: de «epístola de carácter interrogativo» la considera GuILlÉN, «Estilística del silencio», p. 30 (véase asimismo pp. 37-39). 
que se desprende de la lúcida conciencia del ocaso de la vida. La evocación del paisaje entrañable presenta mayor complejidad y elaboración en Machado, que combina la interrogación, con que la interpelación adquiere pleno sentido, y la conjetura basada en el conocimiento y la familiaridad con dicha tierra. Unamuno simplifica el procedimiento, limitándose a la conjetura.

Los procedimientos elocutivos presentan asimismo estrechas analogías. Para la conjetura ambos recurren al futuro (con valor de conjetura). ${ }^{84} \mathrm{~A}$ su vez, ambos utilizan la perífrasis verbal con valor durativo, que enfatiza el proceso evocado, la manifestación de las estaciones en el paisaje. ${ }^{85}$

\section{Conclusiones}

Las influencias literarias consideradas -y no se trata de mera cuestión de fuentesson de doble sentido. En Machado influye el pensador, el sabio; en Unamuno, el poeta. Cada uno toma lo que en el otro admiraba, reconocía como más valioso. En un grupo tan individualista y de trayectorias tan dispersas como la generación del 98, presentan mayor realce las afinidades de Unamuno y Machado, basadas tanto en la mutua simpatía personal y admiración, como en la aceptación por parte del segundo de una suerte de tutela magistral, que, aun cuando remontaba a los mismos inicios de su trayectoria poética, resultaba especialmente oportuna en el momento en que aquélla experimentaba un cambio de rumbo, incorporando una dimensión cívica que liberaba al poeta del solipsismo característico de la estética modernista.

En Machado se trata de la asimilación del pensamiento de Unamuno sobre Castilla, su paisaje y paisanaje y su historia, elevados a clave interpretativa de España. El hombre reflexivo y meditabundo que era Machado acogería como una revelación las reflexiones de su admirado Unamuno, que le permitirían dar -o, al menos, situarlo en el camino de hallar- respuesta a numerosos interrogantes sobre la realidad española surgidos de una honda sensibilidad cívica. La intensa experiencia del paisaje y las gentes de Castilla despertaron en él una vocación paisajística ${ }^{86}$ que no podía permanecer al margen de la reflexión unamuniana desarrollada en En torno al casticismo. Si el contacto con la realidad castellana suscitó el impulso creativo, éste se vería mediatizado y conducido por ese rumbo reflexivo en que del dato geográfico se pasaba a la observación antropológica y a la meditación histórica. El núcleo ideológico básico en que se sustenta la creación de Campos de Castilla viene a corresponder con la asimilación de las ideas de Unamuno, que determinan la forma en que halla expresión la intensa y vital inspiración del paisaje. No se trata, por tanto, de una «presencia» difusa de motivos paisajísticos,${ }^{87}$ sino de la proyección consciente de una serie de ideas asimiladas a través de una lectura que habrá

\footnotetext{
84 «Aún las acacias estarán desnudas/ [...] Habrá trigales verdes...» («A José María Palacio», p. 199); «Ya estarán [...] cayendo las hojas...» («Salamanca en París», p. 84).

85 «¿está la primavera/ vistiendo ya las ramas de los chopos...» («A José María Palacio», p. 199). «Ya estarán [...] cayendo las hojas...» («Salamanca en París», p. 84).

${ }^{86}$ Insiste en lo decisivo de la experiencia directa en el descubrimiento del paisaje por Machado ALBORNOZ, La presencia, p. 144.

${ }^{87}$ Conforme al planteamiento de Albornoz, La presencia, p. 348.
} 
que suponer meditada y entusiasta y que, por tanto, habían pasado a formar parte del bagaje intelectual e ideológico del poeta.

Unamuno reconocía de modo incondicional las excelsas prendas poéticas de Antonio Machado. Especialmente sensible se revelaba ante las más afortunadas acuñaciones verbales del poeta sevillano: sumamente significativo es que un verso posiblemente inspirado en él -el que cierra el poema «Por tierras de España»- le impresionara vivamente. ${ }^{88}$ Así, ante uno de los temas nucleares de su obra, la envidia, Unamuno se muestra atento a su formulación poética. Del mismo modo cabe suponerlo seducido por la feliz construcción poética con que se daba expresión lírica a la nostalgia de la tierra añorada. El pensador se rendía a la capacidad expresiva del poeta.

${ }^{88}$ Albornoz, La presencia, pp. 211, 103. 